\title{
ARTE E ATOS INSTITUCIONAIS ${ }^{1}$
}

Paula Vermeersch

ART AND INSTITUTIONAL ACTS

\section{INTRODUÇÃO}

Os últimos anos da década de 1950, no Brasil, foram marcados por intensos debates artísticos, advindos dos círculos, no eixo Rio-São Paulo, ligados às propostas concretas e neoconcretas. Seria demasiado remontar a essas discussões no detalhe, aqui. É preciso, porém, atentar para o fato de que, na virada para a década 1960, vários artistas brasileiros modificaram o rumo de suas trajetórias; direcionaram suas investigações para campos ou correlatos, mas não necessariamente afins ou opostos, a um ideário de arte abstrata, baseado em investigações sobre os elementos do plano (ponto, linha, cor) e de ligações com os desenvolvimentos da indústria, como algumas tendências da década de 1950.

Não se pretende articular um discurso definitivo nem tampouco unívoco sobre alguns dos processos artísticos da década de 1960 no Brasil. Apenas desejo demonstrar algumas respostas artísticas, no campo da pintura, aos Atos Institucionais, os instrumentos jurídicos pelos quais o regime militar, desde abril de 1964, criou um Estado de exceção, autoritário e baseado numa política econômica marcada por um certo tipo de desenvolvimentismo que pressupunha a exclusão de grande parte da população do País.

A temática social fez com que uma parte da pintura produzida no período retomasse as questões do figurativo, como vemos em um pequeno óleo sem título de Rubens Gerchman (1942-2008) (imagem 1 ; vide anexo), artista falecido recentemente e que foi uma das figuras de proa das discussões plásticas às quais remeto o leitor neste texto. Lembrando os fantoches do expressionismo alemão, os desesperados totens semi-humanos e semibestiais, 
os espectros da política aparecem num colorido de tons frios.

É possível observar tal recurso ao expressionismo em duas cabeças feitas por Ivan Serpa (1923-1973), artista carioca que foi um dos líderes dos eventos neoconcretos. De 1964, os dois óleos escuros que trazem cabeças desfiguradas (imagens 2 e 3) em ambientes sinistros e desesperançados, contrastantes com o mundo de cores vivas e buscas geométricas do mesmo artista nos anos anteriores.

Nesse campo de tensões, é inegável que os acontecimentos políticos da época fizeram grande parte dos artistas brasileiros (músicos, artistas plásticos, atores e diretores de teatro) repensarem suas abordagens. Os acontecimentos dramáticos do início de 1964 culminaram com um golpe, presidido pelas Forças Armadas, que pôs fim ao governo João Goulart sem nenhuma oposição.

Os militares, logo após a tomada do poder, preocuparam-se em implantar uma nova política econômica e legitimar a "Revolução", como foi denominado o golpe por seus defensores e pelos integrantes das Forças Armadas, através de um aparato jurídico específico. Já em 09.04.1964, o general Arthur da Costa e Silva, o tenente-brigadeiro Francisco de Assis Correia de Mello, e o vicealmirante Augusto Hamann Rademaker Grunewald, membros da Junta Militar, assinaram o primeiro Ato Institucional, redigido por Francisco Campos. Com onze artigos, esse Ato, sem número, previa expurgos na corporação das Forças Armadas e na burocracia estatal, a cassação dos direitos políticos de mais de cem pessoas (dentre elas, o ex-presidente João Goulart, o ex-ministro Darcy Ribeiro, o ex-governador do Rio Grande do Sul Leonel Brizola). O Ato tinha validade legal curta, até 15.03.1967, fim do mandato de [Camilo] Castello Branco.

Foram nomeados como ministros da Fazenda e do Planejamento, pelo general Castello Branco, respectivamente, os civis Roberto Campos e Octávio Bulhões, que preocuparam-se em derrubar o que consideravam "entraves" para o "fortalecimento da economia de mercado no País", segundo suas declarações. Uma reforma no sistema de ensino tanto básico quanto superior foi arquitetada por especialistas brasileiros e norte-americanos, para atendimento da exigência de mão-de-obra qualificada; estabeleceu-se uma rede de incentivos para entrada de capitais estrangeiros e para o empresariado brasileiro, como descontos fiscais; foram criadas leis para a caderneta de poupança, e medidas para o incremento das Bolsas de Valores.

Em 1966, foi criado o Fundo de Garantia do Tempo de Serviço, FGTS, resolvendo o impasse provocado pela legislação trabalhista anterior, que não permitia demissões em massa e determinava a liberação de divisas consideráveis para as indenizações dos trabalhadores, o que se confrontava com os interesses empresariais. O FGTS, ao contrário, não regulamentava estabilidade de emprego, e reduzia drasticamente os custos das demissões, porque o fundo é constituído de descontos retirados dos ordenados 
todos os meses. Analistas da época já identificavam o Fundo de Garantia como uma legislação financeira, não trabalhista.

O FGTS, por outro lado, favorecia a política de arrocho salarial. O núcleo do desenvolvimento econômico no regime militar surgiu: FTGS, arrocho (o que resultava num mercado de trabalho barato) e grandes incentivos fiscais para as empresas. Roberto Campos e Bulhões também propuseram a necessidade de se "repensar” a industrialização brasileira: do período Juscelino Kubitschek em diante, a ênfase foi dada aos bens de consumo duráveis, como carros e geladeiras. Os dois ministros do primeiro governo militar limitaram as restrições às compras por crediário para esses bens, mas não incentivaram a produção e o consumo de outros bens que pudessem ser destinados às classes de baixa renda, que tinham seu poder aquisitivo despencando a cada dia, como roupas, bicicletas, fogões e televisores. Esse modelo elitista de consumo só conseguiu ser superado, de maneira restrita, no período do chamado "milagre econômico".

Tanto as reformas no sistema de ensino quanto as medidas econômicas criaram impasses entre o regime e vários setores da sociedade, como o movimento estudantil e toda a gama de associações de trabalhadores rurais e urbanos, e entre os diversos segmentos de oficiais da Marinha, Exército e Aeronáutica.

Um jogo político perigoso - como mostram as imagens de Geraldo Barros (1923-1998) (imagens 4 e 5), artista ligado ao grupo concretista Ruptura uma década antes -, insinuava-se no interior das Forças Armadas: setores ligados à chamada Doutrina da Segurança Nacional (os famosos "linha-dura"), e os que defendiam uma liberalização democrática tutelada passariam a se digladiar em vários momentos da história do regime militar. Alguns oficiais do segundo grupo insistiam, entre 1964 e 1965, que o regime não precisaria temer a opinião popular em embates eleitorais. Em 1965, porém, nas eleições para os governos estaduais, essa crença não se confirmou; a oposição venceu com ampla vantagem em estados estratégicos como a Guanabara e Minas Gerais. Vinte e quatro dias após as eleições, em 17.10.1965, Castello Branco decreta o Ato Institucional $n^{\circ} 2$, uma resposta direta ao resultado das urnas, que previa mais controle do Congresso, fortalecimento do poder Executivo (na forma do direito de baixar decretos-lei e atos complementares no momento que desejasse, e fechar o Congresso, sendo que no período do fechamento deste o Executivo poderia legislar sobre qualquer matéria), cassação de direitos políticos de civis que haviam apoiado o golpe de 1964 (como Carlos Lacerda, ex-governador da Guanabara), e regulamentação mais precisa das cassações. O Ato Complementar $n^{\circ}$ 4, que o acompanhava, decretou o bipartidarismo obrigatório, e dois partidos foram criados, a Arena, base do governo, e o MDB, da oposição.

Começou, segundo Maria Helena Moreira Alves (1984), um movimento pendular, que duraria toda a ditadura: períodos de ares liberalizantes com 
repressão e fim de prerrogativas democráticas (a Doutrina de Segurança Nacional considerava válido esse tipo de "repressão seletiva", já que a sociedade era vista como dividida em setores que deviam ser controlados). Ao fim e ao cabo, os setores linha-dura, porém, tornaram-se vitoriosos (ALVES, 1984).

Em 05.02.1966, três meses após a eleição para governadores, foi decretado o Ato Institucional $\mathrm{n}^{\circ} 3$, com a mesma validade dos anteriores, que rezava que os próximos pleitos estaduais seriam indiretos, e que os prefeitos das cidades maiores e capitais seriam escolhidos pelos governadores (os prefeitos de cidades menores seriam eleitos por meio de voto direto). Isso significava um controle total do governo sobre as unidades da federação; o ano de 1965 havia demonstrado a fragilidade do regime e a insatisfação popular Brasil afora.

A arbitrariedade na função legisladora por parte do Executivo atordoava a oposição. Castello Branco baixara nada mais do que 36 atos complementares, além dos três institucionais. Essa enxurrada legislativa fez a Arena se unir ao MDB para propor algumas emendas constitucionais, e em 12.10.1966, Castello Branco emite um decreto cassando seis deputados federais do MDB. Como o próprio presidente havia prometido à Arena que não decretaria mais cassações, o partido do governo rebela-se, sentindo-se traído. Seu líder e presidente da Câmara dos Deputados, Adauto Lúcio Cardoso, se recusou a realizar as cassações e deu direito de defesa aos acusados, o que gerou uma crise; ele interpretara seu gesto como a defesa do poder civil frente ao militar. Castello Branco não hesitou em fechar o Congresso no dia 20.10.1966, pelo período de um mês. O Executivo decidiu as eleições para a casa, em clima de ocupação por tanques nas cidades mais importantes do país. Ganhou a Arena, e em 07.12.1966, Castello Branco convocou o novo Congresso extraordinariamente, para a aprovação de uma nova Constituição, já escrita, e o Ato Institucional $\mathrm{n}^{\mathrm{o}} 4$ (imagem 6).

Roberto Schwarz (1970), em texto célebre sobre as manifestações culturais de esquerda da época, discute o aparente paradoxo de um regime autoritário, militar, num País onde o cenário cultural era basicamente formado por grupos de esquerda. Apesar da ditadura, uma produção contestatória continuou existindo, consumida por grupos de classe média, como os estudantes. Para Schwarz, tal situação coadunava-se com uma nova fase do desenvolvimento capitalista no País em que a produção ideológica não interessava de perto ao Estado. Os setores da esquerda brasileira, notava o autor, de forma polêmica, também apresentavam um discurso conciliador, patriótico, que muitas vezes utilizava o mesmo jargão que parte dos oficiais das Forças Armadas (basta lembrar que alguns militares eram do Partido Comunista, por exemplo, foram expurgados já nos AI-1 e AI-2).

Nesse tipo de marxismo à brasileira, a noção de "povo" era sentimental, abstrata, e muitos setores antagônicos, confraternizados. Tornaram-se de bom 
tom manifestações nacionalistas, esvaziadas em seu conteúdo. Mais tarde, com o chamado Tropicalismo, a coisa mudou de figura: os tropicalistas não conciliavam opostos, os chocavam e criavam alegorias.

O desejo de luta e o compromisso social como necessidade estética primordial foram as égides até o surgimento do chamado Movimento Tropicalista, em 1967. O zelo cívico e religioso das "Marchas com Deus pela Família e a Liberdade", para os jovens, eram retrocessos, bem com o ufanismo e a paranóia contra o comunismo. Certas atitudes dos governantes militares eram tidas até como ridículas, nesse sentido.

Esses conflitos são bem demonstrados nas crônicas do irreverente humorista Stanislaw Ponte Preta, pseudônimo do jornalista e apresentador de TV Sérgio Porto (1923-1968). Em 1965, Stanislaw publica o Febeapá (Festival de besteira que assola o país), denunciando "as loucuras da sociedade pós-64”. Para ele, o golpe militar se chamava "Redentora", porque havia salvo o país, mas não se sabia bem do quê... Stanislaw escrevia sobre padres que não deixavam as moças namorar, delegados que implicavam com palavrões em estádios de futebol, e criava situações como a do presidente Castello Branco discursando em um Instituto de Surdos-Mudos e sendo aplaudido. Para Stanislaw, o golpe liberara as forças obscurantistas e retrógradas da sociedade brasileira. Escrevia ele: "Pouco depois da 'Redentora', cocorocas de diversas classes sociais e algumas 'otoridades' apareceram, já que a 'Redentora', entre outras coisas, incentivou a política do "dedo-durismo" (a arte de apontar com o dedo um colega, um vizinho, o próximo enfim, como subversivo)" (PALILLO, 1981).

Em 1968, Sérgio Porto sofreu uma tentativa de envenenamento, demonstrando que os setores "cocorocas" não aceitavam piadas. Seu jornalzinho PifPaf, editado por Millôr Fernandes, também foi censurado quando propôs a candidatura de Castello Branco para miss Brasil. De qualquer modo, a herança do humor tornou-se uma das armas mais cortantes contra o regime militar, como demonstraria, depois de 1969 , O Pasquim.

O humor presente no jornalismo também espraiava-se pelas artes plásticas. As conquistas de Lygia Clark e Hélio Oiticica não passavam desapercebidas de quem freqüentava os ambientes culturais da época; mas esse seria um outro discurso. O foco de atenção voltava-se, mais uma vez, a Rubens Gerchman e a Cláudio Tozzi, jovens artistas, o primeiro, carioca, o outro, paulista, que notabilizaram-se por criar telas que remetem à pop art, com materiais inusitados.

Tozzi notabilizou-se pela utilização de tintas industriais em pranchas de madeira, onde recriava clichês jornalísticos. No caso de Usa e abusa (imagem 6), Tozzi faz referência às discussões do movimento estudantil da época, o qual era contrário ao acordo firmado pelo Ministério da Educação com técnicos norte-americanos, para o cumprimento de uma reforma parcial no sistema de educação universitário. 
Já Gerchman apresentou, em 1966, uma de suas criações mais famosas, $A$ bela Lindonéia (imagem 7), criação híbrida em que faz referência às fotos de desaparecidos ou vítimas de crimes passionais nos jornais, que, na época, passaram a se misturar com os cartazes dos procurados pelo regime, os que supostamente praticavam crimes contra a Lei de Segurança Nacional.

A pintura de Tozzi e Gerchman passou a incomodar em 1967/1968. Uma das obras de Tozzi (imagem 8), ${ }^{8}$ no Salão de Arte Moderna de Brasília, foi parcialmente destruída. A técnica, de tinta industrial sobre madeira, usada para tratar de fotos jornalísticas, criou uma espécie de painel warholiano de uma celebridade da época, Che Guevara, mas em vez de uma estetização inofensiva ou de um conteudismo de esquerda mais raso, como certas canções de protesto do período, o significado da luta de Guevara e de sua perseguição não aparece como ponto de chegada de discussões políticas, mas de partida.
É significativo que em 1968, em meio às passeatas e às vésperas do mais terrível dos Atos Institucionais, o AI-5, que suprimiu definitivamente, por vinte anos, as liberdades civis mais básicas no Brasil, Tozzi tenha pintado uma "multidão" (imagem 9); ${ }^{9}$ em vez do "povo" do pensamento de esquerda analisado por Schwarz, uma multidão viva, pulsante, num vórtice que faz lembrar as multidões serpentinadas da pintura de história do século XIX.

Os Atos Institucionais foram instrumentos jurídicos rápidos na ação de liquidar a estrutura de um Estado democrático no Brasil, na articulação dos órgãos da repressão e na extinção de qualquer oposição minimamente organizada no País. Cláudio Tozzi, em entrevista recente, afirmou que "depois do Ato 5 e na década de 1970, meu trabalho passou a ser mais reflexivo" (MAGALHÃES, 2007, p. 37), um índice de como, na pintura, uma arte aparentemente reservada à círculos de elite, tornou-se impossível um discurso que unisse estética e política. 


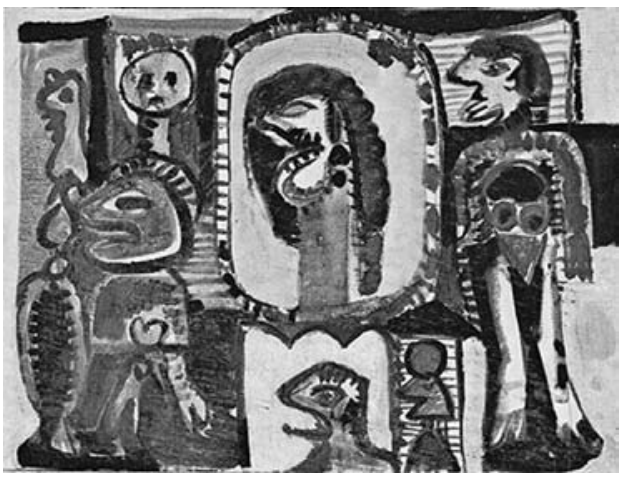

1 - Sem título, de Rubens Gerchman, óleo sobre tela, $46 \mathrm{~cm}$ x $61 \mathrm{~cm}$.

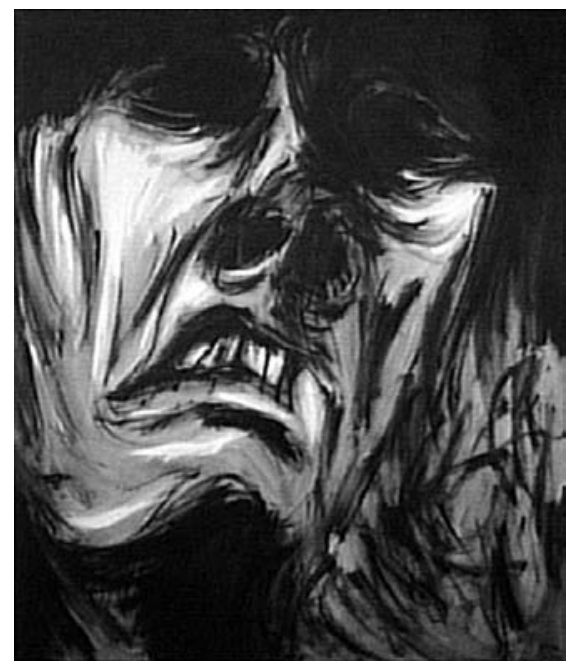

2 - A grande cabeça, de Ivan Serpa, óleo sobre tela, $200 \mathrm{~cm} \mathrm{x} 180 \mathrm{~cm}$. 
590 : ARTE E ATOS INSTITUCIONAIS

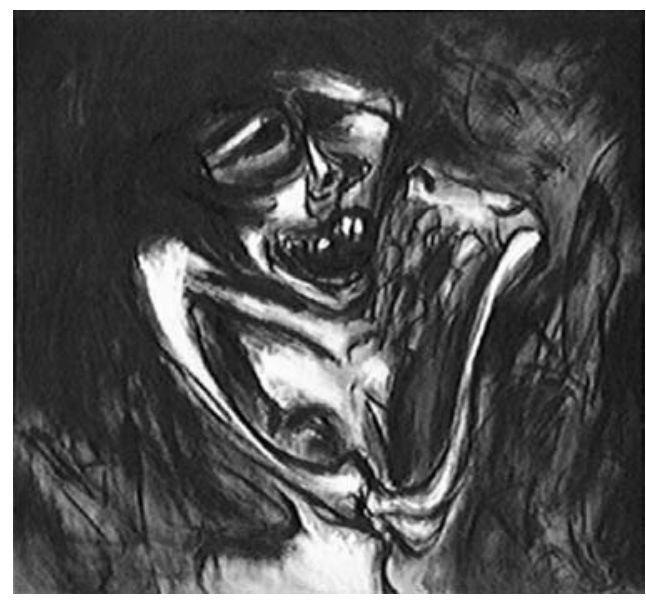

3 - Cabeça, de Ivan Serpa, óleo sobre tela, $100 \mathrm{~cm}$ x $115 \mathrm{~cm}$.

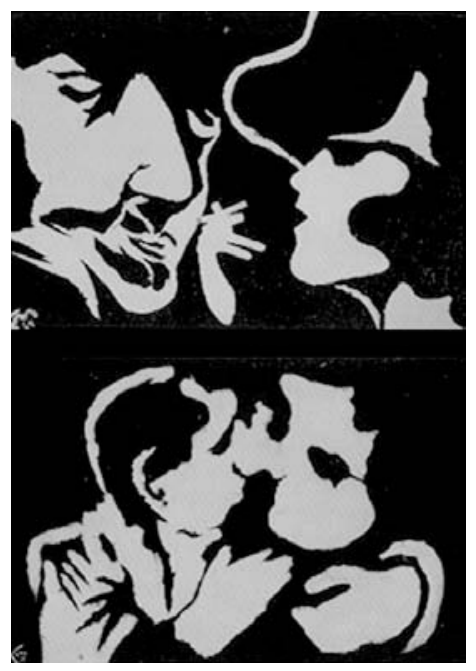

4 - They are playing (Pocker's face). Geraldo de Barros (1923-1998), 1964. Técnica mista sobre cartão, 75 x $110 \mathrm{~cm}$. São Paulo: Pinacoteca do Estado. 


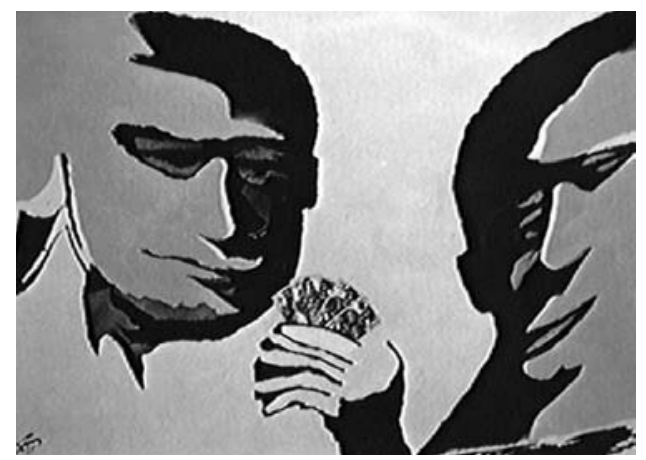

5 - They are playing (Pocker's face), de Geraldo de Barros, técnica mista sobre cartão duplex, $75 \mathrm{~cm}$ x110cm.

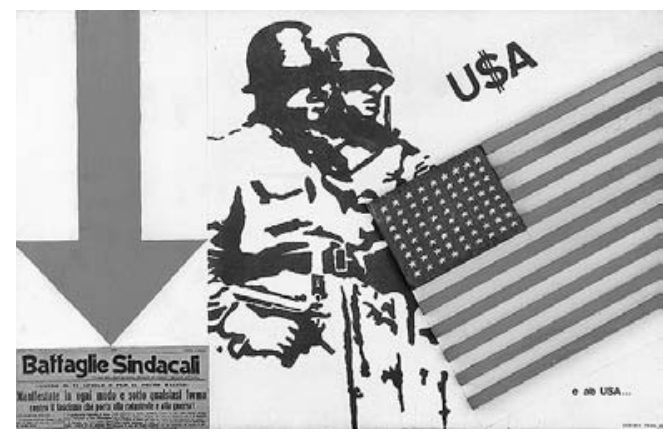

6 - Usa e abusa, de Cláudio Tozzi, tintas em massa e acrílica sobre madeira, $33 \mathrm{~cm}$ x $52 \mathrm{~cm}$.

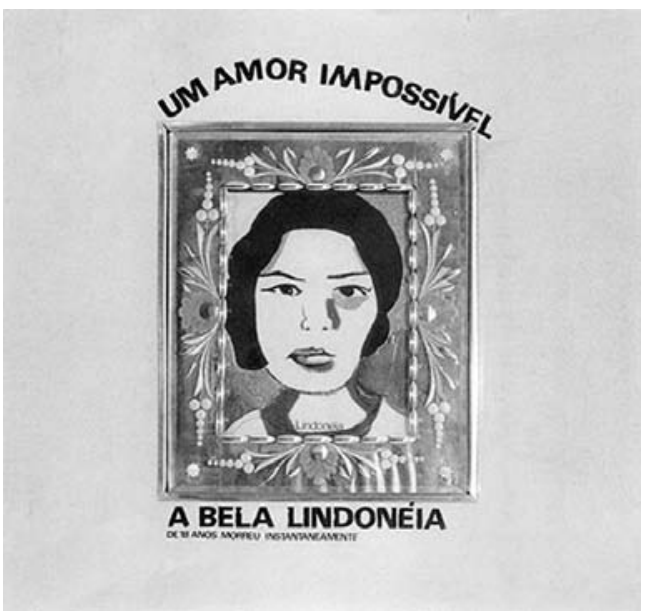

7 - A bela Lindonéia, de Rubens Gerchman, tinta acrílica, vidro bisotê e colagem sobre madeira, $90 \mathrm{~cm}$ x $90 \mathrm{~cm}$. 
592 : ARTE E ATOS INSTITUCIONAIS

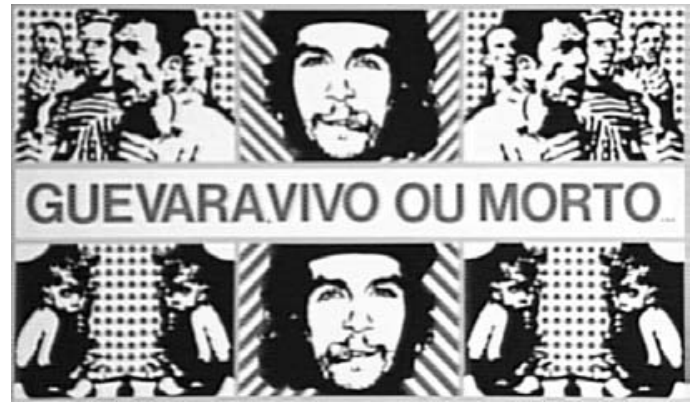

8 - Guevara vivo ou morto, de Cláudio Tozzi, tintas em massa e acrílica sobre aglomerado, $175 \mathrm{~cm} \mathrm{x} 300 \mathrm{~cm}$.

Esta obra foi parcialmente destruída por motivos políticos no Salão de Brasília e, hoje, encontra-se em Buenos Aires, na Argentina.

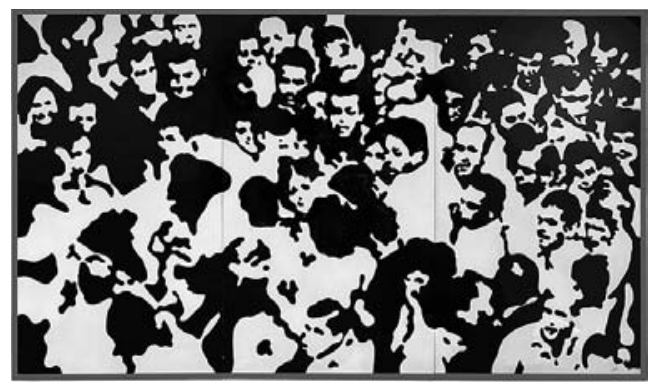

9 - Multidão, de Cláudio Tozzi, tinta em massa e acrílica sobre aglomerado, $175 \mathrm{~cm} \mathrm{x} 300 \mathrm{~cm}$. 


\section{NOTAS}

1 Este artigo é fruto de várias preocupações, surgidas ainda no curso de graduação em Ciências Sociais da Unicamp, na forma de projeto de Iniciação Científica e monografia (1998). Essas inquietações voltaram por

\section{REFERÊNCIAS BIBLIOGRÁFICAS}

Fontes primárias e documentos de época: Atos Institucionais. Disponível em:

<http://www.acervoditadura.rs.gov.br>.

'Tropicália é uma piada', O Estado de S.Paulo, 07.06.1968

Folha de São Paulo. 14 de dezembro de 1968.

Revista Veja. 13 de novembro de 1968. .20 de novembro de 1968 .

Estudos e análises sobre a ditadura militar e manifestações culturais:

ALVES, Maria Helena Moreira. Estado e oposição no Brasil (1964-1984). Petrópolis: Editora Vozes, 1984. Cronologia da década de 60. Folha de São Paulo. MAGALHÃES, Fábio. Rubens Gerchman. São Paulo: Lazuli Editora; Companhia Editora Nacional, 2006. .Claudio Tozzi. São Paulo:

Lazuli Editora; Companhia Editora Nacional, 2007. NAVES, Rodrigo. 'Hélio Oiticica: entre a violência diversas vezes nesses anos, e o texto pretende dar conta de algumas delas; alguns trechos remontam diretamente à monografia. Agradecimentos a José Rodrigo Rodriguez e Guilherme Gomez de Andrade. e o afeto', 'Um azar histórico: sobre a recepção das obras de Hélio Oiticica e Lygia Clark'. In: $O$ vento e o moinho. Ensaios sobre arte moderna e contemporânea. São Paulo: Companhia das Letras, 2007 PALILlO, Maria Célia Rua de Almeida. São Paulo: Abril Cultural, 1981.

SCHARWZ, Roberto. 'Remarques sur la culture et la politique au Brésil'. In: Les Temps Moderns, $\mathrm{n}^{\mathrm{O}} 288,1970$

STEPAN, Alfred. Authoritharian Brazil - Origins, Policies And Future. New Haven and London: Yale University Press, 1973.

$$
\text { Os militares na política - As }
$$

mudanças de padrões da vida brasileira. Rio de Janeiro: Artenova, 1975.

VERMEERSCH, Paula. Pão e circo. A imaginação como contra-poder. Monografia de final de curso de graduação em Ciências Sociais. IFCH-Unicamp, 1998.
Rua Padre Vieira, 673 - apto 53 Bosque - 13015-301 Campinas - SP - Brasil paulavermeerschlagmail.com

\section{Paula Vermeersch}

Mestre em Sociologia, em História da Arte e da Cultura E DOUTORA EM TEORIA E HISTÓRIA LITERÁRIA

Fol docente de História da ARTE E Estética na PUC de Campinas e no Departamento de Artes Plásticas DO INSTITUTO DE ARTES [UnicAmp]

Atualmente, DEDICA-SE ÀS PESQUisAs EM SEU PÓS-DOUTORAMENTO, NA MESMA UNIVERSIDADE 